\title{
STUDI PERGESERAN WAKTU KEBERANGKATAN ARUS LALU LINTAS DAN ARUS JENUH DASAR PADA SIMPANG BERSINYAL UNTUK PENDEKAT SATU ARAH (STUDI KASUS : SIMPANG BERSINYAL DI RUAS JALAN BRIGJEN SLAMET RIYADI, SOLO)
}

\author{
Ganang Noor Cholis ${ }^{1}$ ), Amirotul M.H.M. ${ }^{2}$ ), Slamet J. Legowo ${ }^{3}$ ) \\ 1) Mahasiswa Fakultas Teknik, Prodi Teknik Sipil, Universitas Sebelas Maret \\ 2) Pengajar Fakultas Teknik, Prodi Teknik Sipil, Universitas Sebelas Maret \\ 3) Pengajar Fakultas Teknik, Prodi Teknik Sipil, Universitas Sebelas Maret \\ Jl. Ir. Sutami 36A, Kentingan Surakarta 57126; Telp. (0271) 634524, Fax 662118 \\ Email : Ganangnc@gmail.com
}

\begin{abstract}
Intersection is place with bigh vebicle conflict. The solution to reduce number of conflict is by adding traffic light. Installation traffic light increase delays, time of vehicle departure and base saturation flow per meter. This study aims to analyze base saturation flow per meter which can be used as reference for MKJI 1997 and determine variations time departure of vebicles at intersections with traffic lights. This study used Time Slice Method. Primary data consist of traffic flow data, departure time vehicles data, intersection geometric data, traffic light duration data and land function data around intersections from direct surveys in the field by taking samples on Slamet Riyadi road. The survey was conducted during peake bours and non peak hours. Secondary data consist of population data and road network maps were obtained from relevant agencies. Based on the results 8 from 10 results the average time of vehicle departure indicates the delay of vehicle departure. While for the calculation $S o / m$ obtained 7 from 10 data shows the results of the base saturation flow per meter coefficient which is greater than 600 pcu/hours/ $\mathrm{m}$ (the standard set by MKJI 1997) with a range of 636,7249 - 906,7352 pcu/ hours / $\mathrm{m}$.
\end{abstract}

Keywords : signalized intersections, base saturation flow per meter, time slice method, time variation of vehicle departure.

\begin{abstract}
Abstrak
Simpang jalan merupakan daerah dengan konflik kendaraan yang tinggi. Solusi untuk mengurangi konflik adalah dengan penambahan lampu lalu lintas. Pemasangan lampu lalu lintas dapat menambah tundaan, waktu keberangkatan kendaraan lebih awal dan arus jenuh dasar per meter yang besar. Penelitian ini bertujuan untuk menganalisis besaran arus jenuh dasar per meter yang nantinya dapat sebagai rujukan dalam perbaikan MKJI 1997 dan mengetahui variasi waktu keberangkatan kendaraan pada simpang dengan adanya lampu lalu lintas. Penelitian dilakukan menggunakan metode time slice. Data primer mencakup data arus lalu lintas, data variasi waktu keberangkatan kendaraan, data geometrik simpang, data durasi lampu lalu lintas dan data fungsi lahan sekitar simpang yang diperoleh melalui survei langsung di lapangan dengan mengambil sampel di jalan Slamet Riyadi Surakarta. Survei dilakukan saat jam puncak dan jam tidak puncak. Data sekunder berupa data jumlah penduduk dan peta jaringan jalan diperoleh dari instansi terkait. Berdasarkan hasil analisis 8 dari 10 hasil rata-rata waktu keberangkatan kendaraan menunjukkan adanya tundaan keberangkatan kendaraan. Sementara hasil analisis perhitungan $\mathrm{S}_{\mathrm{o}} / \mathrm{m}$ didapatkan 7 dari 10 data menunjukkan hasil koefisien arus jenuh dasar permeter yang lebih besar dari 600 $\mathrm{smp} / \mathrm{jam} / \mathrm{m}$ (standar yang ditetapkan MKJI 1997) dengan range 636,7249 - 906,7352 smp/jam/m.
\end{abstract}

Kata kunci: arus jenuh dasar per meter, metode time slice, simpang bersinyal, variasi waktu berangkat kendaraan.

\section{PENDAHULUAN}

Ketika besar nilai arus lalu lintas sudah mendekati kapasitas jalan, perlu adanya upanya untuk mengurangi konflik yang terjadi. Salah satu daerah dengan konflik arus lalu lintas yang tinggi adalah pada persimpangan jalan. Simpang jalan merupakan daerah umum dimana terjadi pertemuan antara dua atau lebih jalan. Salah satu upaya mengurangi konflik pada simpang adalah dengan pemasangan lampu lalu lintas termasuk pada Jalan Slamet Riyadi. Walaupun dapat mengurangi konflik yang terjadi, akan tetapi pemasangan lampu lalu lintas pada persimpangan jalan menambah tundaan dan waktu keberangkatan lebih awal pada setiap kendaraan yang akan melewati simpang jalan. Semakin besar tundaan yang terjadi maka semakin besar pula kerugian yang dialami oleh pengendara baik itu dari segi waktu maupun bahan bakar yang digunakan. Pemasangan lampu lalu lintas pada persimpangan jalan menyebabkan terjadinya kehilangan waktu pada saat arus kendaraan mulai berangkat. Kehilangan waktu pada waktu hijau efektif saat permulaan kendaraan akan berangkat disebut dengan kehilangan awal. Hal ini menyebabkan variasi waktu keberangkatan kendaraan pada simpang bersinyal.

Variasi waktu pada saat keberangkatan kendaraan yang lebih lambat dapat berdampak pada semakin berkurangnya arus lalu lintas yang masuk ke simpang jalan. Bukan hanya itu saja, arus lalu lintas yang tinggi juga 
memiliki kecenderungan untuk membuat terjadinya perubahan perilaku pada pengendara. Semakin tinggi arus lalu lintas membuat pengendara semakin tidak sabar dan cenderung melakukan pelanggaran lalu lintas. Perubahan perilaku pengendara yang terjadi dan semakin bertambahnya jumlah kendaraan tiap tahunnya, dapat berpengaruh pada nilai arus jenuh dasar lalu lintas.

Besar nilai arus jenuh dasar (So/m) pada suatu simpang memiliki sifat berbanding lurus terhadap lebar pendekat efektifnya. Jadi semakin lebar ukuran pendekat suatu simpang, maka dapat menyebabkan nilai arus jenuh dasar yang terjadi pada simpang tersebut juga akan semakin besar, begitu pula sebaliknya. Hal ini berdasarkan perhitungan arus jenuh dasar yang termuat dalam MKJI 1997. Penelitian ini menggunakan metode Time Slice untuk analisis data lalu lintas. Tujuan dari penelitian adalah untuk mengetahui besar variasi waktu keberangkatan lalu lintas dan besar nilai arus jenuh dasar per meter yang terjadi di Jalan Slamet Riyadi. Hasil dari penelitian ini diharapkan dapat menjadi acuan dalam menentukan besarnya kapasitas jalan yang optimal. Hal ini didasarkan bahwa nilai arus jenuh dasar menjadi acuan untuk menentukan kapasitas pendekat.

\section{LANDASAN TEORI}

\section{Simpang Bersinyal}

Simpang bersinyal adalah persimpangan jalan yang dilengkapi dengan lampu lalu lintas atau biasa disebut APILL (Alat Pemberi Isyarat Lalu Lintas).

\section{Manual Kapasitas Jalan Indonesia 1997}

Manual kapasitas jalan Indonesia adalah buku manual/panduan yang digunakan untuk menghitung kapasitas dan perilaku lalu lintas segmen-segmen jalan di Indonesia. Standar yang ditetapkan MKJI 1997 untuk arus jenuh dasar per meter adalah $600 \mathrm{smp} / \mathrm{jam} / \mathrm{m}$.

\section{Waktu Keberangkatan Kendaraan}

Waktu keberangkatan kendaraan dapat diartikan sebagai waktu yang dibutuhkan kendaraan untuk melewati garis batas henti kendaraan pada simpang ketika lampu lalu lintas menunjukkan isyarat warna hijau.

\section{Rata-rata (Mean)}

Nilai rata-rata digunakan untuk menentukan hasil perhitungan waktu keberangkatan kendaraan. Nilai rata-rata merupakan nilai yang ditentukan dengan menjumlah seluruh nilai data sampel yang didapatkan kemudian dibagi dengan jumlah data yang digunakan. Berikut merupakan rumus yang digunakan untuk mencari nilai rata-rata (mean) :

Keterangan:

$$
\bar{x}=\frac{1}{n} \sum_{i=1}^{n} x_{i}
$$

$\mathrm{x}=$ Nilai rata - rata

$\mathrm{n}=$ Jumlah data

$\mathrm{xi}=$ Nilai sampel ke-i

\section{Metode Time Slice}

Metode time slice adalah metode yang digunakan untuk melakukan analisis terhadap data arus jenuh dengan cara membagi-bagi data keberangkatan kendaraan berdasarkan interval waktu. Pembagian interval waktu yang digunakan dengan durasi 6 detik tiap potong (slice). Jumlah interval waktu tiap slice disesuaikan dengan durasi waktu lampu lalu lintas berwarna hijau. Setelah mendapatkan data lapangan yang dibutuhkan, berikutnya adalah melakukan analisis data yaitu dengan perhitungan emp kendaraan berat (HV), kendaraan ringan (LV), dan sepeda motor (MC). Rumus yang digunakan untuk melakukan perhitungan nilai emp pada masing-masing potongan waktu adalah sebagai berikut :

$$
(\Sigma L V x \text { emp LV }+\Sigma H V x \text { emp HV }+\Sigma M C x \text { emp MC }) \times \frac{3600}{t}=Q
$$

Keterangan :

Q $\quad=$ volume kendaraan bermotor $(\mathrm{smp} / \mathrm{jam})$

emp LV = nilai ekuivalen mobil penumpang untuk kendaraan ringan

emp HV = nilai ekuivalen mobil penumpang untuk kendaraan berat

emp MC = nilai ekuivalen mobil penumpang untuk sepeda motor

LV $\quad=$ kendaraan ringan (Light Vebicle)

HV $\quad=$ kendaraan berat (Heavy Vebicle)

MC = sepeda motor (Motor Cycle) 


\section{Satuan Mobil Penumpang}

Satuan mobil penumpang merupakan satuan yang menggambarkan nilai arus lalu lintas berdasarkan komposisi kendaraan. Arus lalu lintas berdasarkan satuan mobil penumpang dapat didapatkan dengan mengkalikan dengan ekivalensi mobil penumpang untuk masing-masing tipe kendaraan.

\section{Arus Jenuh}

Arus jenuh adalah arus keberangkatan rata-rata antrian di dalam suatu pendekat simpang selama sinyal lampu lalu lintas berwarna hijau. Arus jenuh dinyatakan dalam satuan smp per jam hijau (smp/jam hijau). Persamaan yang digunakan untuk menghitung besarnya nilai arus jenuh suatu persimpangan adalah sebagai berikut :

Keterangan :

$\mathrm{S}=$ Arus jenuh (smp/waktu hijau),

So $=$ Arus jenuh dasar (smp/waktu hijau),

$\mathrm{F}_{\mathrm{CS}}=$ Faktor penyesuaian akibat ukuran kota (Factor Country Size),

$\mathrm{F}_{\mathrm{SF}}=$ Faktor penyesuaian akibat hambatan samping (Factor Side Friction),

$\mathrm{F}_{\mathrm{G}}=$ Faktor penyesuaian akibat kelandaian jalan (Factor Gradient),

$\mathrm{F}_{\mathrm{p}}=$ Faktor penyesuaian akibat parkir tepi jalan (Factor Parkir),

$\mathrm{F}_{\mathrm{LT}}=$ Faktor penyesuaian kapasitas akibat adanya pergerakan belok kiri (Factor Left Turn),

$\mathrm{F}_{\mathrm{RT}}=$ Faktor penyesuaian kapasitas akibat adanya pergerakan belok kanan (Factor Right Turn).

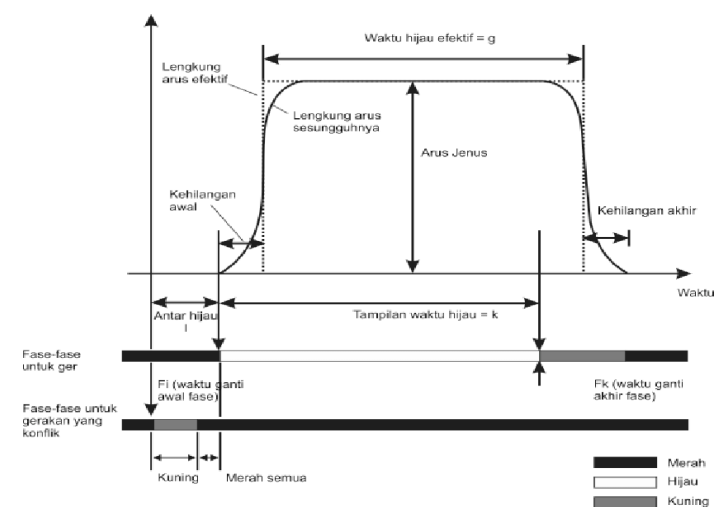

Gambar 1. Model Dasar Arus Jenuh Sumber : MKJI 1997

Tabel 1. Ekivalensi Mobil Penumpang (EMP) Tiap Tipe Kendaraan pada Simpang Bersinyal

\begin{tabular}{ccc}
\hline \multirow{2}{*}{ Tipe Kendaraan } & Emp \\
\cline { 2 - 3 } & Pendekat Terlindung & Pendekat Terlawan \\
\hline LV & 1,0 & 1,0 \\
HV & 1,3 & 1,3 \\
MC & 0,2 & 0,4 \\
\hline
\end{tabular}

Sumber : MKJI 1997

\section{Arus Jenuh Dasar}

Menurut MKJI 1997, arus jenuh dasar didefinisikan sebagai besarnya keberangkatan antrian di dalam lengan pendekat simpang selama kondisi ideal. Nilai arus jenuh dasar pada pendekat dengan tipe arus terlindung dapat dihitung dengan menggunakan rumus sebagai berikut :

$$
\text { So }=600 \times \mathrm{We}
$$

Keterangan :

So = Arus jenuh dasar ( $\mathrm{smp} / \mathrm{jam} / \mathrm{hijau})$

We = lebar pendekat efektif (m) 


\section{METODE}

Penelitian ini menggunakan metode analisis statistik deskripstif untuk mengetahui variasi waktu keberangkatan kendaraan dan metode time slice untuk menganalisis nilai arus jenuh yang terjadi di lapangan. Data yang digunakan terdiri dari data primer dan data sekunder. Data primer merupakan data yang berupa data geometrik simpang, fase dan durasi sinyal, serta data arus lalu lintas. Sedangkan data sekunder yang digunakan berupa data jumlah penduduk dan juga peta jaringan jalan kota Solo.

\section{HASIL DAN PEMBAHASAN}

Contoh perhitungan waktu keberangkatan kendaraan pada Simpang Gendengan saat jam puncak (06.45-08.45 WIB) dapat dilihat pada Tabel 2 berikut

Tabel 2. Data Waktu Keberangkatan Kendaraan pada Simpang Gendengan saat Jam Puncak (06.45-08.45 WIB)

\begin{tabular}{cccccccc}
\hline $\begin{array}{c}\text { No } \\
\text { Siklus }\end{array}$ & $\begin{array}{c}\text { Waktu } \\
\text { Keberangkatan }\end{array}$ & $\begin{array}{c}\text { No } \\
\text { Siklus }\end{array}$ & $\begin{array}{c}\text { Waktu } \\
\text { Keberangkatan }\end{array}$ & $\begin{array}{c}\text { No } \\
\text { Siklus }\end{array}$ & $\begin{array}{c}\text { Waktu } \\
\text { Keberangkatan }\end{array}$ & $\begin{array}{c}\text { No } \\
\text { Siklus }\end{array}$ & $\begin{array}{c}\text { Waktu } \\
\text { Keberangkatan }\end{array}$ \\
\hline 1 & 2 & 19 & 0 & 37 & 1 & 55 & 2 \\
2 & -2 & 20 & 0 & 38 & 0 & 56 & 0 \\
3 & 1 & 21 & 1 & 39 & 0 & 57 & 1 \\
4 & 2 & 22 & 1 & 40 & -1 & 58 & 2 \\
5 & 0 & 23 & 0 & 41 & 2 & 59 & 0 \\
6 & 0 & 24 & 0 & 42 & 2 & 60 & 2 \\
7 & 0 & 25 & -1 & 43 & 0 & 61 & 1 \\
8 & 1 & 26 & -1 & 44 & 1 & 62 & 0 \\
9 & -2 & 27 & 0 & 45 & 2 & 63 & 1 \\
10 & 1 & 28 & 1 & 46 & 1 & 64 & 1 \\
11 & 1 & 29 & -1 & 47 & 1 & 65 & 0 \\
12 & 1 & 30 & 2 & 48 & 2 & 66 & 1 \\
13 & 1 & 31 & 1 & 49 & 2 & 67 & 0 \\
14 & -1 & 32 & 1 & 50 & 1 & 68 & 0 \\
15 & 0 & 33 & 1 & 51 & 1 & 69 & 0 \\
16 & 1 & 34 & 1 & 52 & 0 & 70 & 0 \\
17 & 2 & 35 & 1 & 53 & 4 & Total & 46
\end{tabular}

Menghitung rata-rata waktu keberangkatan

$$
\begin{aligned}
\bar{x} & =\frac{1}{n} \sum_{i=1}^{n} x_{i} \\
\bar{x} & =46 / 70 \\
\bar{x} & =0,6571 \text { detik }
\end{aligned}
$$

Berdasarkan penelitian di tiap pendekat simpang bersinyal yang diteliti, diperoleh hasil rata-rata selisih waktu keberangkatan kendaraan seperti yang ditampilkan pada tabel $3-4$.

Tabel 3. Waktu Keberangkatan Kendaraan Tiap Simpang pada Jam Puncak (06.45-08.45 WIB)

\begin{tabular}{cccccc} 
Waktu & \multicolumn{3}{c}{ Frekuensi Kejadian } \\
\cline { 2 - 5 } $\begin{array}{c}\text { Keberangkatan } \\
\text { (detik) }\end{array}$ & $\begin{array}{c}\text { Simpang } \\
\text { Gendengan }\end{array}$ & $\begin{array}{c}\text { Simpang } \\
\text { Sriwedari }\end{array}$ & $\begin{array}{c}\text { Simpang Hotel } \\
\text { Novotel }\end{array}$ & $\begin{array}{c}\text { Simpang } \\
\text { Ngarsopuro }\end{array}$ & $\begin{array}{c}\text { Simpang } \\
\text { Nonongan }\end{array}$ \\
-4 & 0 & 0 & 0 & 0 & 2 \\
-3 & 0 & 0 & 0 & 0 & 5 \\
-2 & 2 & 1 & 0 & 1 & 10 \\
-1 & 5 & 10 & 18 & 45 & 21 \\
0 & 23 & 47 & 16 & 2 & 7 \\
1 & 27 & 5 & 0 & 0 & 0 \\
2 & 12 & 0 & 0 & 0 & 0 \\
3 & 0 & 0 & & 0 & 0 \\
\hline
\end{tabular}




\begin{tabular}{cccccc}
\hline Jumlah & 70 & 80 & 80 & 80 & 63 \\
\hline $\begin{array}{c}\text { Rata-rata Waktu } \\
\text { Kebearngkatan } \\
\text { (detik) }\end{array}$ & 0,6571 & 0,1875 & 0,0000 & $-0,1375$ & $-0,8030$ \\
\hline
\end{tabular}

Tabel 4. Waktu Keberangkatan Kendaraan Tiap Simpang pada Jam Tidak Puncak (9.00-11.00 WIB)

\begin{tabular}{|c|c|c|c|c|c|}
\hline \multirow{2}{*}{$\begin{array}{c}\text { Waktu } \\
\text { Keberangkatan } \\
\text { (detik) }\end{array}$} & \multicolumn{5}{|c|}{ Frekuensi Kejadian } \\
\hline & $\begin{array}{c}\text { Simpang } \\
\text { Gendengan }\end{array}$ & $\begin{array}{l}\text { Simpang } \\
\text { Sriwedari }\end{array}$ & $\begin{array}{c}\text { Simpang Hotel } \\
\text { Novotel }\end{array}$ & $\begin{array}{c}\text { Simpang } \\
\text { Ngarsopuro }\end{array}$ & $\begin{array}{c}\text { Simpang } \\
\text { Nonongan }\end{array}$ \\
\hline-2 & 1 & 1 & 0 & 0 & 2 \\
\hline-1 & 6 & 10 & 12 & 7 & 9 \\
\hline 0 & 34 & 53 & 54 & 47 & 35 \\
\hline 1 & 22 & 10 & 14 & 21 & 20 \\
\hline 2 & 6 & 5 & 0 & 4 & 3 \\
\hline 3 & 1 & 1 & 0 & 1 & 0 \\
\hline Jumlah & 70 & 80 & 80 & 80 & 66 \\
\hline $\begin{array}{c}\text { Rata-rata Waktu } \\
\text { Kebearngkatan } \\
\text { (detik) }\end{array}$ & 0,4110 & 0,1375 & 0,0250 & 0,3125 & 0,1884 \\
\hline
\end{tabular}

Berdasarkan hasil penelitian waktu keberangkatan kendaraan menggunakan metode analisis statistik yang ditampilkan pada Tabel 2 dan Tabel 3, hasil analisis rata-rata waktu keberangkatan kendaraan di lengan pendekat yang telah diteliti pada 5 simpang, 8 dari 10 hasil rata-rata waktu keberangkatan kendaraan menunjukkan adanya tundaan keberangkatan kendaraan. Keberangkatan kendaraan yang paling cepat terjadi pada Simpang Nonongan saat jam puncak yaitu sebesar -4 detik.

Contoh perhitungan arus jenuh pada Simpang Gendengan dengan jumlah siklus 70 saat jam puncak (06.45-08.45 WIB) dapat dilihat pada Tabel 5 berikut ini

Tabel 5. Data Arus Jenuh Simpang Gendengan pada Jam Puncak (06.45-08.45 WIB)

\begin{tabular}{ccccc}
\hline \multirow{2}{*}{$\begin{array}{c}\text { Interval } \\
\text { (detik) }\end{array}$} & \multicolumn{3}{c}{ Arus Jenuh (SMP / 1260 detik) } \\
\cline { 2 - 5 } & MC & LV & HV & M \\
\cline { 2 - 5 } & $(1)$ & $(2)$ & $(3)$ & $(1)+(2)+(3)$ \\
\hline $0.0-6.0$ & 256,2 & 141 & 0 & 397,2 \\
$6.1-12.0$ & 252 & 333 & 0 & 585 \\
$12.1-18.0$ & 124,6 & 327 & 2,6 & 454,2 \\
\hline
\end{tabular}

$$
\begin{aligned}
\Sigma \text { siklus } & =70 \\
\mathrm{~S} & =(\Sigma \mathrm{LV} \times \mathrm{emp} \mathrm{LV}+\Sigma \mathrm{HV} \times \mathrm{emp} H \mathrm{HV}+\Sigma \mathrm{MC} \times \mathrm{emp} \mathrm{MC}) \times \frac{7200}{t} \\
& =(397,2+585+454,2) \times \frac{7200}{18 \times 70} \\
& =1436,4 \times 5,72 \\
& =8208 \mathrm{smp} / 2 \mathrm{jam} \\
& =4104 \mathrm{smp} / \mathrm{jam}
\end{aligned}
$$

Berdasarkan penelitian di tiap pendekat simpang bersinyal yang diteliti, diperoleh hasil arus jenuh dasar per meter seperti yang ditampilkan pada tabel $6-7$.

Tabel 6. Arus Jenuh, Arus Jenuh Dasar, dan Arus Jenuh Dasar Per Meter Tiap Simpang pada Jam Puncak (06.45-08.45 WIB)

\begin{tabular}{cccccc}
\hline Simpang & $\begin{array}{c}\text { Arus Jenuh } \\
(\text { Smp/jam) }\end{array}$ & $\begin{array}{c}\text { Faktor } \\
\text { Penyesuaian }\end{array}$ & $\begin{array}{c}\text { Arus Jenuh } \\
\text { Dasar } \\
\mathbf{( S m p / j a m )}\end{array}$ & $\begin{array}{c}\text { Lebar } \\
\text { Efektif }(\mathbf{m})\end{array}$ & $\begin{array}{c}\text { Arus Jenuh Dasar Per } \\
\text { Meter } \\
(\text { Smp/jam/m) }\end{array}$ \\
\cline { 2 - 6 } & $\mathbf{a}$ & $\mathbf{b}$ & $\mathbf{c}=\mathbf{a} / \mathbf{b}$ & $\mathbf{d}$ & $\mathbf{e}=\mathbf{c} / \mathbf{d}$ \\
\hline Simpang Gendengan & 4104 & 0,8553 & 4798 & 6,7 & 716,1539 \\
\hline
\end{tabular}




\begin{tabular}{lccccc} 
Simpang Sriwedari & 5522 & 0,8170 & 6759 & 13 & 519,9461 \\
Simpang Hotel Novotel & 4773 & 0,8060 & 5922 & 9,3 & 636,7249 \\
Simpang Ngarsopuro & 4643 & 0,7606 & 6104 & 9 & 678,2727 \\
Simpang Nonongan & 5984 & 0,7332 & 8161 & 9 & 906,7352 \\
\hline
\end{tabular}

Tabel 7. Arus Jenuh, Arus Jenuh Dasar, dan Arus Jenuh Dasar Per Meter Tiap Simpang pada Jam Tidak Puncak $(9.00-11.00 \mathrm{WIB})$

\begin{tabular}{lccccc}
\hline \multicolumn{1}{c}{ Simpang } & $\begin{array}{c}\text { Arus Jenuh } \\
\text { (Smp/jam) }\end{array}$ & $\begin{array}{c}\text { Faktor } \\
\text { Penyesuaian }\end{array}$ & $\begin{array}{c}\text { Arus Jenuh } \\
\text { Dasar } \\
\text { (Smp/jam) }\end{array}$ & $\begin{array}{c}\text { Lebar } \\
\text { Efektif (m) }\end{array}$ & $\begin{array}{c}\text { Arus Jenuh Dasar Per } \\
\text { Meter } \\
\text { (Smp/jam/m) }\end{array}$ \\
\cline { 2 - 6 } $\mathbf{~}$ & $\mathbf{a}$ & $\mathbf{b}=\mathbf{a} / \mathbf{b}$ & $\mathbf{d}$ & $\mathbf{e}=\mathbf{c} / \mathbf{d}$ \\
\hline Simpang Gendengan & 3626 & 0,8592 & 4220 & 6,7 & 629,8304 \\
Simpang Sriwedari & 4725 & 0,8192 & 5768 & 13 & 443,7214 \\
Simpang Hotel Novotel & 4395 & 0,8132 & 5404 & 9,3 & 581,0634 \\
Simpang Ngarsopuro & 4413 & 0,7505 & 5880 & 9 & 653,2933 \\
Simpang Nonongan & 5559 & 0,7239 & 7678 & 9 & 853,1666 \\
\hline
\end{tabular}

Berdasarkan hasil penelitian arus jenuh dasar per meter yang dihitung menggunakan metode time slice pada Tabel 4 - Tabel 5, didapatkan 7 dari 10 hasil perhitungan arus jenuh dasar per meter $(\mathrm{So} / \mathrm{m})$ memiliki nilai arus jenuh dasar per meter (So/m) yang melebihi standar yang telah ditetapkan oleh MKJI 1997 dengan range 715,5334 994,0283 smp/jam/m. Sedangkan 3 hasil perhitungan lainnya berada di bawah standar yang telah ditetapkan MKJI 1997 dengan range 442,7753 - 593,5237 smp/jam/m.

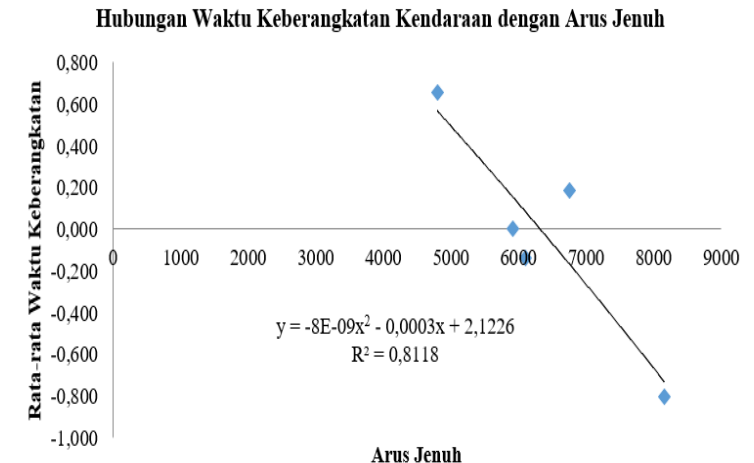

Gambar 2. Grafik Hubungan Arus Jenuh dengan Ratarata Waktu Keberangkatan Kendaraan pada Jam Puncak (06.45-08.45 WIB)

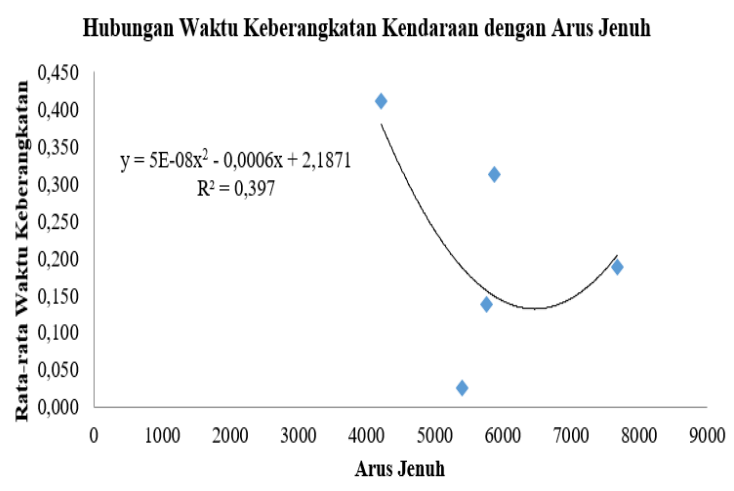

Gambar 3. Grafik Hubungan Arus Jenuh dengan Ratarata Waktu Keberangkatan Kendaraan pada Jam Tidak Puncak (09.00-11.00 WIB)

Berdasarkan grafik pada Gambar 2 dan Gambar 3 di atas, dapat dilihat bahwa pada jam puncak (06.45-08.45 WIB), sebesar $81,18 \%$ faktor yang mempengaruhi terjadinya pergeseran waktu keberangkatan kendaraan adalah arus jenuh dan 18,82\% sisanya adalah disebabkan oleh faktor lain. Sedangkan pada jam puncak (10.00-12.00 WIB), sebesar 39,70\% faktor yang mempengaruhi terjadinya pergeseran waktu keberangkatan kendaraan adalah arus jenuh dan 60,30\% sisanya adalah disebabkan oleh faktor lain. 
Hubungan Waktu Keberangkatan Kendaraan dengan Arus Jenuh Dasar Per Meter

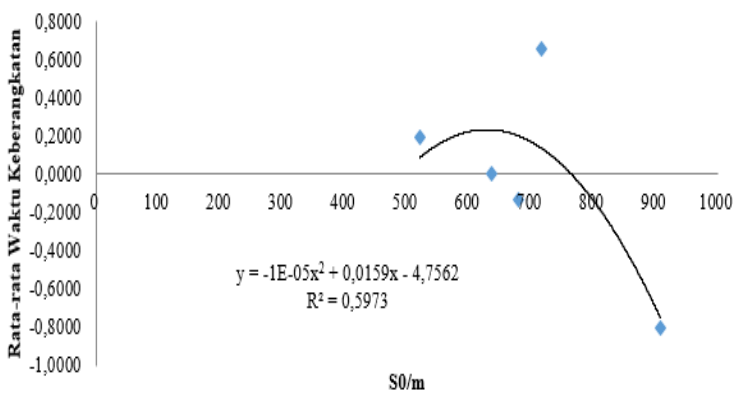

Gambar 4. Grafik Hubungan antara Arus Jenuh Dasar Per Meter dengan Rata-rata Waktu Keberangkatan Kendaraan pada Jam Puncak (06.4508.45 WIB)
Hubungan Waktu Keberangkatan Kendaraan dengan Arus Jenuh Dasar Per Meter

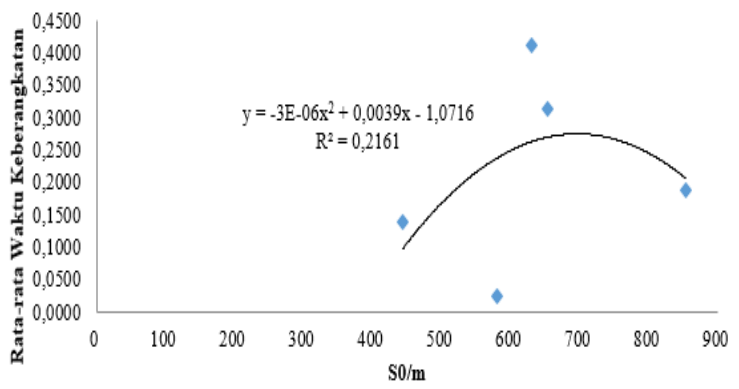

Gambar 5. Grafik Hubungan antara Arus Jenuh Dasar Per Meter dengan Rata-rata Waktu Keberangkatan Kendaraan pada Jam Tidak Puncak (09.00-11.00 WIB)

Berdasarkan grafik pada Gambar 4 dan Gambar 5 di atas, dapat dilihat bahwa pada jam puncak (06.45-08.45 WIB), sebesar 59,73\% faktor yang mempengaruhi terjadinya pergeseran waktu keberangkatan kendaraan adalah arus jenuh dasar per meter dan 40,27\% sisanya adalah disebabkan oleh faktor lain. Sedangkan pada jam puncak (10.00-12.00 WIB), sebesar 21,61\% faktor yang mempengaruhi terjadinya pergeseran waktu keberangkatan kendaraan adalah arus jenuh dasar per meter dan 78,39\% sisanya adalah disebabkan oleh faktor lain.

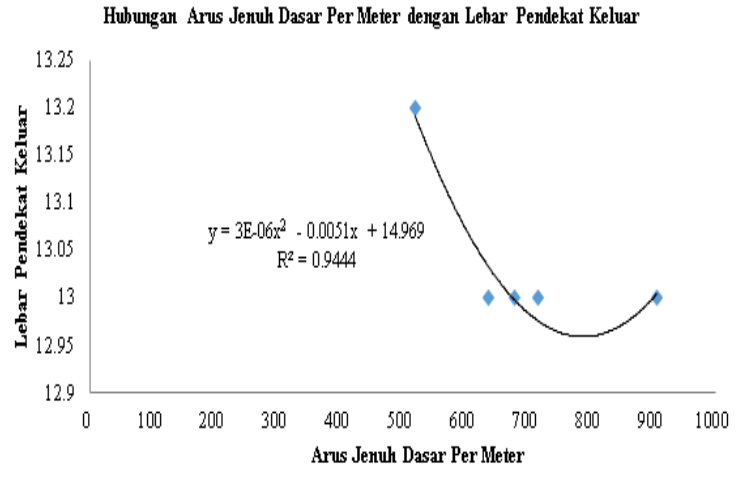

Gambar 6. Grafik Hubungan antara Arus Jenuh Dasar Per Meter pada Jam Puncak dengan Lebar Pendekat Keluar

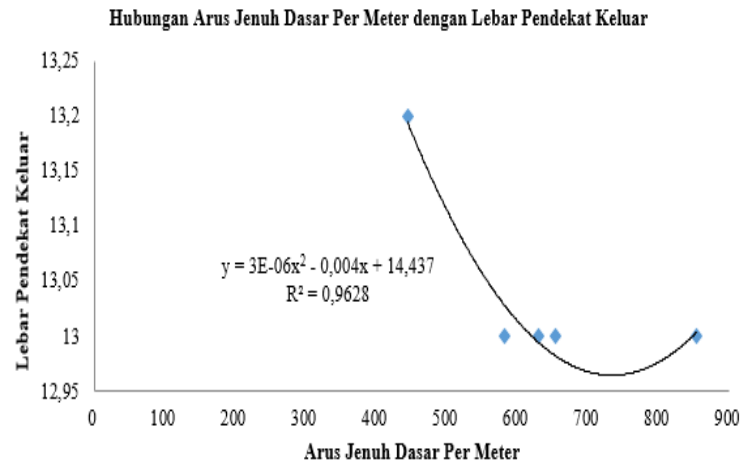

Gambar 7. Grafik Hubungan antara Arus Jenuh Dasar Per Meter pada Jam Tidak Puncak dengan Lebar Pendekat Keluar

Berdasarkan grafik pada Gambar 6 dan Gambar 7 di atas, dapat dilihat bahwa pada jam puncak (06.45-08.45 WIB), sebesar $94,44 \%$ faktor yang mempengaruhi arus jenuh dasar per meter adalah lebar pendekat keluar dan 5,66\% sisanya adalah disebabkan oleh faktor lain. Sedangkan pada jam tidak puncak (9.00-11.00 WIB), sebesar $96,28 \%$ faktor yang mempengaruhi arus jenuh dasar per meter adalah lebar pendekat keluar dan 3,72\% sisanya adalah disebabkan oleh faktor lain.

\section{SIMPULAN}

Berdasarkan hasil analisis rata-rata waktu keberangkatan kendaraan di lengan pendekat yang telah diteliti pada 5 simpang, 8 dari 10 hasil rata-rata waktu keberangkatan kendaraan menunjukkan adanya tundaan keberangkatan kendaraan. Keberangkatan kendaraan yang paling cepat terjadi pada Simpang Nonongan saat jam puncak yaitu sebesar -4 detik. Sedangkan untuk analisis arus jenuh dasar per meter yang telah dilakukan, 7 dari 10 hasil perhitungan arus jenuh dasar per meter $(\mathrm{So} / \mathrm{m})$ memiliki nilai arus jenuh dasar per meter $(\mathrm{So} / \mathrm{m})$ yang melebihi standar yang telah ditetapkan oleh MKJI 1997 dengan range 715,5334 - 994,0283 smp/jam/m. Sedangkan 3 hasil perhitungan lainnya berada di bawah standar yang telah ditetapkan MKJI 1997 dengan range 442,7753 $593,5237 \mathrm{smp} / \mathrm{jam} / \mathrm{m}$.

\section{UCAPAN TERIMAKASIH}


Penyusun mengucapkan banyak terima kasih kepada yang terhormat Ibu Amirotul Musthofiah HM, S.T.,M.Sc. dan Bapak S. J. Legowo, S.T., M.T., selaku Dosen Pembimbing skripsi yang telah memberikan waktu, pikiran, dan tenaga dalam membimbing penyusun dengan penuh kesabaran, sehingga penyususn dapat menyelesaikan penyusunan skripsi ini dengan baik. Tidak lupa penyusun juga mengucapkan banyak terimakasih kepada seluruh pihak yang baik secara langsung maupun tidak langsung turut membantu dalam penyusunan laporan skripsi ini.

\section{REFERENSI}

1997. Manual Kapasitas Jalan Indonesia (MKJI). Departemen Pekerjaan Umum Direktorat Jenderal Bina Marga.

Bowoputro, Hendi, M.Zainul Arifin, Lutfi Djakfar, dan Rahayu Kusumaningrum. 2014. Kajian Arus Jenuh Pada Simpang Bersinyal di Kota Malang Bagian Selatan. Jurnal Rekayasa Sipil Volume 8, No.2 - 2014 ISSN $1978-5658$.

Jonathan, Sarwono. 2006. Metode Penelitian Kuantitatif dan Kualitatif. Graha Ilmu. Yogyakarta

Muntazar, M.Isya dan Sugiarto. 2017. Model Arus Jenuh Dasar Pada Simpang Bersinyal Studi Kasus pada Simpang dengan Lengan Efektif Satu dan Dua Lajur Di Banda Aceh. Jurnal Teknik Sipil. Universitas Syiah Kuala

Panjaitan, Tri Utamy Yohana. 2018. Studi Variasi Waktu Keberangkatan Lalu Lintas dan Perbandingan Arus Jenuh Dasar Metode Time Slice dengan Arus Jenuh Dasar MKJI 1997 Pada Simpang Bersinyal dengan Short Time Countdown Timer. Program Studi Teknik Sipil Fakultas Teknik. Universitas Sebelas Maret Surakarta.

Pratina, Ginung. 2018. Analisis Pergeseran Waktu Keberangkatan Kendaraan Dan Arus Jenuh Pada Simpang Bersinyal Yang Dilengkapi Dengan Full Time Countdown Timer. Program Studi Teknik Sipil Fakultas Teknik. Universitas Sebelas Maret Surakarta.

Prasetyowati, Dindin Astriani. 2016. Analisa Statistik (Teori Dan Aplikasi Menggunakan Spss). Fakultas Ilmu Komputer. Universitas Indo Global Mandiri. Palembang.

Shang, Huayan. Zhang, Yiming dan Fan, Lang. 2014. Heterogeneous Lanes Saturation Flow Rates at Signalized Intersections. Systems Engineering Society of China. Beijing Jiaotong University 